$$
\begin{aligned}
& \text { TEI }=11+? \\
& \left\{\begin{array}{c}
0 \\
-10
\end{array}\right. \\
& 510=179: 2: 9
\end{aligned}
$$

Ninth Quarterily Report ....

October, November, December, 1989
DOE/PC/79938-MII

DW2020284

\title{
Studies of Caupled Chemical and Catalytic Coal Conversion Methods
}

\author{
Contract 22-87PC79938 \\ Department of Chemistry \\ The University of Chicago \\ Chicago, IIIInois 60637
}

\author{
Leon M. Stock, Principal Investigator \\ Kuntal Chatterjee and Michael Ettinger \\ Research Staff
}

\section{DISCLAIMER}

This report was prepared as an accoumt of work spponsorad by an ugency of the Unitod States Gowerament. Neither the United Stutes Covernment not any agestey thereof, nor any of their ermployeses, makes any warranty, express or impliod, or assumes any legal liability or responatbility for the socurecy, ocmpletenow, or usefulness of any information, apparalus, product, or process discliosed, of represents that the une would not infringe privately owned rights. Reference beretin to any apecific commercial product, procesas, or service by trade name, trademark,

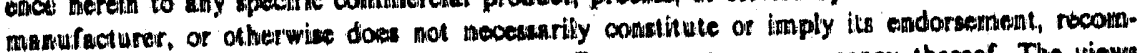
memctation, of favoring by the Unirod States Government or any agency thereof. The views and opiniona of authors expresued berein do not neceavartly state or reflect those of the Uaitied Sintes Government of any apency thereof.

\section{MASTER}


Coal Solubllizotion. Promotion of the C-Rlkylation Reaction by n-Butyllithium and Potassium t-Butoride.

\title{
Kuntal Chotterjee,I Mikio Mlyokers and Leon M. Stock* Department of Chemistry, The University of Chicego Chicogo, Illinois 6063?
}

\section{ILink Foundation Fellow, 198J-1990.}

TDepartinent of Applied Chemistry, Osaka University, Japan.

\begin{abstract}
A new base catalyzed C-alkylation reaction that employs a mixture of $n$-butyllithium and potassium t-buioxide in refluxing heptane to produce coal anions that are subsequently treated with $n$-alkyl halides at $0^{\circ} \mathrm{C}$ has been developed. Almost quantitative pyridine solubilization was achieved by C-octylation of a Lower Kittanning coal, PSOC 1197. C-Octylation was less successful for the solubilization of bituminous Illinois No. 6 coal, APCSP 3, and subbituminous Wyodak coal, APCSP 2, which gave 35 and $33 \%$ soluble material, respectively. Their O-methyl cerivatives yielded 43 and $20 \%$ soluble material in the same reaction. The observations are in accord with the concept of Ouchi and his associates that higher rank coals, although more aromatic in character, have lower degree of polymerization than low rank coals. Relatively mild chemical reactions, such as $\mathbf{C}$ alkylation, that lead to modest changes in roolecular dimensions, can disrupt intermolecular forces and accomplish solubilization.
\end{abstract}




\section{Introduction}

Most chemical reactions that have been investigated for the transformation of codl to soluble products disrupt strong covalent linkages.1,2 More recently, interest has been directed to simple alkylation reactions that can alter the non-bonded intermolecular interactions that contribute to the binding of large coal molecules in the solid state. ${ }^{2}$ These strategies are based on the idea that the introduction of an O-alkyl group can eliminate hydrogen bonding interactions and the introduction of a C-alkyl group can disrupt intermolecular polarization forces. Whereas, 0 -alkylation does not generally enhance the solubility of either high or low rank coals to a significant degrec, ${ }^{2,3}$ C-Alkylation is especially effective for some high rank coals, ${ }^{3-10}$ Indeed, C-octylation with sodium amide in liquid ammonia converts at least one low volatile bituminous coal from the Lower Kittanning Seam, PSOC 1197, in which polarization forces are clearly more important than hydrogen bonding forces, into a substance that is $90 \%$ soluble in pyridine.9

The strengths of the bases that were used in the alkylation of this high rank coal influenced the results significantly. There was a clear change in the solubility of the products that were obtained from the Lower Kittanning coal with sodium hexamethyldisilazide $\left(\mathrm{p} \mathrm{K}_{\mathrm{a}} 26\right)$, sodium amide $\left(\mathrm{pK}_{\mathrm{a}} 35\right)$ and lithium diisopropylamide $\left(\mathrm{pK}_{\mathrm{a}} 36\right) .9$ The weakest base, sodium hexamethyldisilazide, provided only $16 \%$ soluble material during butylation, whereas the stronger bases, sodium amide and lithium disopropylamide produced more than $50 \%$ soluble material in the same reaction. These observations suggested that other stronger bases might be even more effective reagents for solubilization, and led us to consider the use of $n$ butyllichium $\left(\mathrm{pK}_{\mathrm{a}} 42\right)$ for $\mathrm{C}$-alkylation. This reagent should be able to abstract protons from the weakly acidic aromatic carbon acids, $\mathrm{pK}_{\mathrm{a}}>35$, as well as from the relatively strong benzylic carbon acids, $\mathrm{pK}_{\mathrm{a}}<30$. 
The use of alkyllithium bases in coal chemistry is not new. Lazarov and his coworkers used n-butyllithium in tetrahydrofuran for the alkylation of some carbonrich Bulgarian and German coals. ${ }^{6}$ They reported that the maximum solubility in tetrahydrofuran, $38 \%$, was obtained for a bituminous coal containing about $88 \% \mathrm{C}$. Chambers and his coworkers performed C-alkylation reactions on the Lower Kittanning coal, PSOC 1197, with three alkyllithium bases with nominal pKa values between 19 and 31.8,10 They carried out the reactions in a selective way to investigate the carbon acids in this coal, and only low solubilities were realized for thrice-alkylated reaction products.8,10

Our initial attempts to use $n$-butyllithium in tetrahydrofuran or $n$-butyllithium with tetramethylethylene diamine in tetrahydrofuran failed.9 These reactions produced much less soluble material than desired. After additional preliminary work, we found that a 1:1 mixture of $n$-butyllithium and potassium 2 -butoxide (conveniently designated as super base) was much more effective. $n$-Butyllithium is itself a strong base; however, it has been shown that potassium $t$-butoxide enhances its basicity in an unprecedented manner. ${ }^{11}$ When treated with super base, hydrocarbons in the low acidity range, $\mathrm{pK}_{\mathrm{a}} 35-50$, undergo clean hydrogen metal exchange.11 The reasons for the success of this reagent have not been established, and several viable interpretations have been advanced by other workers in the field. Specifically, it has been suggested that the alkylpotassium compound, which can be formed in an ixchange reaction and can be isolated under suitable conditions, is the active or'fanometallic reagent. 12 Schlosser, however, has shown that such compounds, for example $n$-butylpotassium, are inferior to super base.11 He alternatively ho's suggested that the alkoxide anion enhances the reactivity of the alkyllithium by the formation of mixed clusters of the organometallic compound and the metallic aikoxide. 11 It has aiso been proposed that the alkoxide anion 
kinetically enhances the proton transfer reactions of the thermodynamically strong alkyllithium base. 13

We were led to investigate super base by the work of Bates and his coworkers, who exploited the high basicity of this reagent to convert dimethylphenols to diethylanisoles. 14 In the present study, super base has been applied for the $\mathrm{C}$ alkylation of one low and one high volatile bituninous coal and a subbituminous coal. The work with the higher rank bituminous coal with its low oxygen cuntent and very low phenolic content was successful, and the unmodified lower rank coals were then studied. Subsequently, these low rank coals, which are rich in phenolic groups, were methylated with tetraburylammonium hydroxide and methy! iodide to obviate the complications of the high negative charge density that would be produced in the coal macromolecule by the basic reagents. This strategy enabled the exclusive assessment of C-alkylation on their solubilization.

\section{Esperimental Section}

Materials. A lower Kittanning coal, PSOC 1197, was obtained frorn the Pennsylvania State University Sample Bank and an Mlinois No. 6 bituminous coal, APCSP 3, and a Wyodak rubbituminous coal, APCSP 2, were supplied by the Premium Sample Prograrn of the Argonne National Laboratory. The analytical data for all the coals are summarized in Table I. The coal samples were dried at $110^{\circ} \mathrm{C}$ under vacuum for 48 hours prior to use. The solubility of the pristine coals in pyridine were 5, 27 and $9 \%$ (daf) for the Lower Kittanning, Illinois No. 6 and Wyodak coals, respectively.

n-Heptane (Aldrich) was shaken with concentrated sulphuric acid, and subsequently distilled. The purified solvent was stored in the presence of molecular sieve 5A. 
Methyl, $n$-butyl and $n$-octyl iodides (Aldrich) were also dried by molecular sieve 5A. Pyridine was purified by distillation. The other chemicals such as nbutyllithium (1.6 M solution in hesane), potassium $t$-butoxide, tetrabutylammonium hydroxide, dibenzofuran, ammonium chloride, methanol and hexane were used as received from the Aldrich Chemical Company.

O-Methylation. Both Illinois No. 6 and Wyodak coals were methylated with tetrabutylammonium hydroxide and methyl iodide by the method of Liotta and his coworkers. 15 The coal $(25 \mathrm{~g})$ was suspended in dry tetrahydrofuran $(150 \mathrm{~mL})$ and stirred for 30 minutes. Tetrabutylammonium hydroxide $(80 \mathrm{~mL}, 91 \mathrm{mmoles})$ was added and the mixture was stirred overnight. Then, methyl iodide (25.4 grams, 179 mmoles) was added to the reaction mixture, which was stirred for 48 hours. The reaction mixhure was acidified with $1 \mathrm{~N}$ hydrochloric acid to $\mathrm{pH} 2$. The flask was then placed on a rotary evaporator to remove tetrahydrofuran, and the product was collected by filtration and washed with $50 \%$ aqueous methanol (about 4L). The methylation was repeated a second time to ensure that all the phenolic hydroxyl groups were methylated. After thorough washing, the products were dried at $1100^{\circ} \mathrm{C}$ under vacuum for 48 hours. The infrared spectra of the products of both coals showed substantial decreases in the hydroxyl stretching frequencies near 3400 $\mathrm{cm}^{-1}$ together with increases in the carbon-hydrogen stretching frequencies near $2850-2900 \mathrm{~cm}^{-1}$. New carbon-oxygen stretching frequencies near $1250 \mathrm{~cm}^{-1}$ due to the methyl ethers were also evident. From the increase in weight and from the elemental analysis of the products, it was determined that about 5 and 4.3 methyl groups per $100 \mathrm{~mol}$ carbon were introduced into Illinois No. 6 and Wyodak coal, respectively during the O-methylation. These O-methylated Ilinois No. 6 and Wyodak coals were used as starting materials for all the seactions described in the subsequent paragraphs. 
Reaction Procedure for the Coals. The C-alkylation reactions of the coal samples were carried out essentially as reported by Bates and his coworkers. 14 $n$-Heptane $(170 \mathrm{~mL})$, potassium $t$-butoxide $(5.04 \mathrm{~g}, 45$ mmoles) and $n$-butyllithium ( $30 \mathrm{~mL} 1.6 \mathrm{M}$ solution in hexane, 45 mmoles) were added to a flame dried flask . The mixture was stirred at room temperature for 15 minutes, the coal sample $(1 \mathrm{~g})$ was added, and the solution was refluxed for 6 hours. The initial black solution turned brown when refluxing began. $n$-Butyl iodide ( $11.0 \mathrm{~g}, 60$ mmoles) in $n$-heptane $(70 \mathrm{~mL})$ was added dropwise to this coal anion suspension, after cooling the flask at $0{ }^{\circ} \mathrm{C}$. The mixture was stirred for 48 hours at room temperature to ensure complete alkylation of the coal anions. The residual base was quenched by adding ammonium chloride and methanol. The solvents and the excess $n$-buryl iodide were removed by a rotary evaporator. The product was carefully collected and washed with dilute aqueous hydrochloric acid $(2 \mathrm{~L})$, aqueous methanol $(3: 1,20 \mathrm{~L})$, and $n$ hexane $(4 \mathrm{~L})$. The product was dried to constant weight at $110^{\circ} \mathrm{C}$ under vacuum for 48 hours. The number of alkyl groups that were introduced per $100 \mathrm{~mol}$ carbon was estimated from the increase in weight of the product.

A portion of each product was subjected to Soxhlet extraction with pyridine. The solubility of the coal was verified in some experiments by filtering the solution through a Nucleopore polycarbonate membrane filter (pore size $0.8 \mu \mathrm{m}$ ); the residue on the filter was always less than $2 \mathrm{mg}$ per gram coal. In other representatative cases, the isolated soluble solid coal was redissolved in pyridine and a readily filterable solution was obtained. These facts establish that the products were truly soluble in pyridine.

Reaction of Dibenzofuran. The reaction of dibenzofuran was conducted in a similar manner. Dibenzofuran $(0.84 \mathrm{~g}, 5 \mathrm{mmol})$ was allowed to react with $n$ - 
butyllithium ( $15 \mathrm{~mL} 1.6 \mathrm{M}$ solution in hexane, $22.5 \mathrm{mmol}$ ) and potassium $t$-butoxide (2.52g, $22.5 \mathrm{mmol})$ in refluxing heptane $(100 \mathrm{~mL})$ for 6 hours. Methyl iodide $(7.1 \mathrm{~g}, 50 \mathrm{mmol})$ was added at $0^{\circ} \mathrm{C}$ and the mixture was stirred for 48 hours at room temperature. The excess base was neutralized with ammonium chloride and methanol, the solvent and the remaining methyl iodide were evaporated and the product was extracted into ether which was washed with water and dried over anhydrous magnesium sulphate. Ammonium chloride and methanol, rather than methyl iodide, were used to neutralize the reaction mixture in another experiment. The product distributions were established by conventional GC-MS procedures.

Analyses of Products. Solution phase ${ }^{13} \mathrm{C}$ and ${ }^{2} \mathrm{H}$ NMR spectra of the extracts of the alkylated coals were recorded using a Varian XL-400 spectrometer. FT-IR of the products were recorded with a Nicolet Model 20SX spectrometer. Potassium bromide pellets of the coal products $(2-4 \mathrm{wt} \%)$ were dried at $90^{\circ} \mathrm{C}$ for 24 hours before recording the spectra.

The analysis of the products that were obtained from dibenzofuran was conducted by GC-MS using Hewlett Packard 5970 series mass detector ( $70 \mathrm{ev)}$ connected to 5890 gas chromatograph ( OV-101 capillary column, $100-180^{\circ} \mathrm{C}, 5^{\circ} \mathrm{C} / \mathrm{min}$ ). The ${ }^{1}$ H-NMR spectrum of the product in chloroform-d was recorded with the University of Chicago $500 \mathrm{MHz}$ spectrometer.

\section{Hesults and Discussion}

As already mentioned in the Introduction, all the reactions that were carried out with super base in tetrahydrofuran were unsuccessful. The degree of alkylation was low and the solubilities of the products were extremly low. Even though tetrahydrofuran would have been an excellant solvent for the alkylation of coal, it 
could not be used with super base. Although alkyllithiums can be used successfully in tetrahydrofuran at very low temperatures, it is well known that these reagents are consumed through the cleavage of the solvent via $\alpha$-lithiation at ambient temperatures. 16 This consideration led us to adopt Bates's conditions; 14 fortunately, the reactions of the coals could be successfully carried out in heptane.

We began our work with the Lower Kittanning coal, PSOC 1197. This high rank coal is only $5 \%$ soluble in pyridine. Previous work established that sodium amide promoted butylation yielded a product that was $50 \%$ soluble in pyridine. 9 However, Chambers and his coworkers found that only 1.8 methyl groups per 100 mol carbon were introduced into this coal by three succ. :sive treatments with different alkyllithium bases and that the thrice methylated coal was merely $30 \%$ soluble in pyridine.8,10

The results for the super base promoted C-alkylation reaction of Lower Kittanning coal are summarized in Table $\mathbf{I}$.

The information for the C-butylation reactions with sodium amide in liquid ammonia and with n-butyl lithium in tetrahydrofuran are included with the results for the super base in heptane for convenient comparison. The butylated products that were obtained through the reaction of $n$-butyllithium in tetrahydrofuran arns through the reaction of sodium amide in ammonia were 10 and $50 \%$ soluble in pyridine, respectively. In contrast, butylation with super base in heptane provided a $90 \%$ soluble product. There is evidently direct relationship between the strength of base and the solubility of this C-alkylated coal. The information that is presented in Table II suggests that about 4 butyl groups per $100 \mathrm{~mol}$ carbon are introduced into the coal in the super base system. The reactions with $n$-butyllithium 
alone and with sodium amide introduce about 1 and 2 butyl groups per 100 mol carbon, respectively.

Super base is an especially effective reagent for the cllkylation and solubilization of this coal. The reason for its effectiveness was explored by determination of the degree of solubilization that could be realized by treat.ent of the coal with base and protonation. Unreacted coal is only 5\% soluble in pyridine, and the reaction with sodium amide in liguid an:monia followed by protonation yielded a product that was $9 \%$ soluble in pyridine.9 On the basis of this observation, it was concluded that modest concentrations of sodium amide did not significantly alter the molecular framework through hydrocarbon elimination reactions or other base catalyzed fragmentation reactions. 9 However, when the reaction was performed with super base in heptane and the intermediate was treated with ammonium chloride in methanol, the recovered coal was $39 \%$ soluble in pyridine. Clearly, the base alone must have altered the molecular structure either through base-catalyzed rearrangement reactions or, more probably, through hydrocarbon elimination reactions, such as the one shown in equations (1) and (2), that could reduce the dimensions of the macromolecule.

Coase $=$ Cost

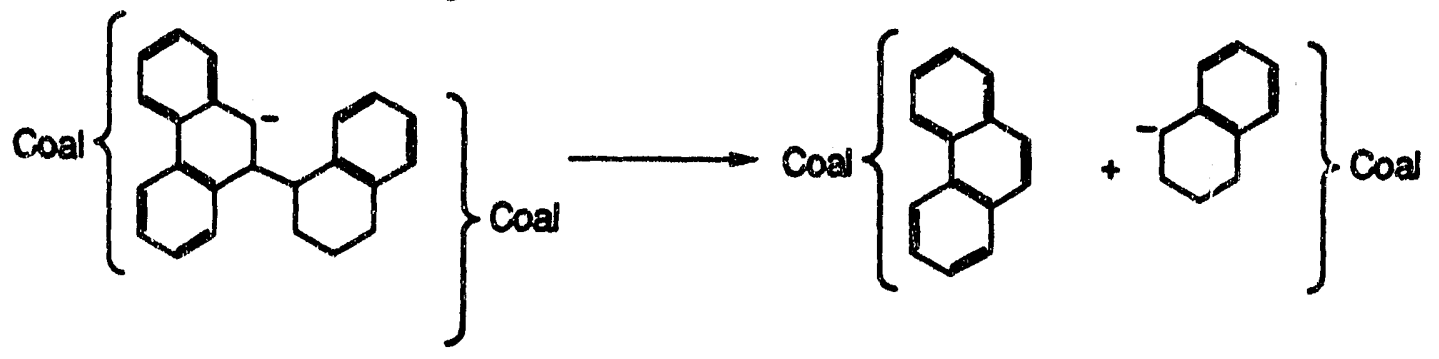


Carbon-carbon bond cleavage reactions of this kind are uncommon. However, Grovenstein's review indicates that benzylic anions can readily be cleaved from carbanions. 17 Under normal circumstances, base catalyzed readdition reactions are expected to take place. However, we propose that the bydrocarbon units in the coal are adequately strained such that bond cleavage reactions, equations 1 and 2 , would release strain energy within the coal macromolecule and be irreversible. Further investigations on the base promoted carbon-carbon bond cleavage reactions in hydrocarbons are currently underway.

In any event, the results imply that these elimination reactions are much less significant with weaker bases, and we infer that the stronger base increases the concentration of coal carbanions in the reaction medium and, therefore, increases the opportunity for tautomerization and fragmentation reactions. These fragmentation reactions probably have apprecible activation energies and their rates may be significantly enhanced in heptane at $98{ }^{\circ} \mathrm{C}$. In point of fact, the reactions of Lower Kittanning coal that were performed with super base under identical conditions, but at room temperature, yielded only $18 \%$ soluble material. Consequently, we infer that the rates of the fragmentation reactions of the anions in coat depend not only on the concentration of carbanions but also on the reaction temperature. The much higher degree of solubility (92\%) that is achieved after treatment with base and C-octylation presumably results from the disruption of intermolecular polarization forces by the long alkyl groups as discussed previously. 9

We further explored the scope of the reactions of super base by the study of two lower ranking coals. The results for Illinois No. 6 and Wyodak coal are summarized in Tables III and IV. 
The low rank coals contain large amounts of oxygen atoms, and a significant portion of them occur in heterocycles. ${ }^{18}$ Hence, we studied dibenzofuran to investigate the chemical reactions that might occur with these substances in the coal under the influence of super base. In the first experiment, dibenzofuran was treated with super base in refluxing heptane for 6 hours, and the reaction mixture was quenched with ammonium chloride and methanol. Analysis of the product showed that $95 \%$ of the starting material was recovered, and about $5 \%$ of the cleavage product, 2-phenylphenol, was obtained.

In the next experiments, the reaction mixtures were treated with methyl iodide. The reiction with dibenzofuran was performed in a similar manner to that of coal. Excess base as well as excess methyl iodide was used. Many products including mono-, di-, tri-, and even heptamethyl derivatives were observed in the GC-MS analysis. A reaction pathway for the rmethylation reaction is shown in Scheme 1. Initially, a hydrogen atom is abstracted from the aromatic ring to provide the orthometallated compound. The initial met lylation reaction yields 2 -methyldibenzofuran. The methyl hydrogen atoms are benzylic and more acidic than the aromatic hydrogen atoms. Thus, subsequent anionization occurs at the benzylic position and the second methyl group is introduced selectively at the benzylic carbon atom.

Since the main emphasis was to study the influence of C-alkylation on solublization, the 0-methylated coals were used as starting materials for most of the reactions. The results for Illinois No. 6 coal, Tables III and IV, show the influeri $z$ of the base that was used for C-alkylation on solubilization. About 27\% of the pristine coal sample was extractable in pyridine. The octylated products with potassium hydroxide, sodium amide and super base produced 33, 32 and 
$43 \%$ soluble materials, respectively. Super base is clearly a more effective reagent that the other bases.

The entries in Table IV show the influence of the size of the alkyl group on solubility. The pyridine solubility of the products that were obtainut after the reaction maixt-res were quenched with electrophiles ranging from ummonium chloride to octul lodide were apt very different. There is no conelation between the nature of alkyl group and solubility. Illinois No. 6 coal behaves entirely differently than Lower Kittanning coal in the sense that the length of the alkyl group coes not alker solubility. The results that bave been obtained for the $\mathrm{C}$. alkylation of these two coals parallel the obsersations of Wachowska and her collaborators for the reductive alkylution of high and low rank coalis.19

We were surprised by the observation that no more than 2 to 4 C-alkyl groups were introduced into the coal, especially because diberizofuran so readily experienced multiple alkylation. This and many other activated aromatic compounds are readily metallated by strong bases and alkylated. 20 Several experiments were conducted 80 investigate this feature of the reaction with coal. First there was no evidence for the metallation of aromatic compounds in Illinois No. 6 coal. When the coal anion was quenched with deuterium oxide, no deuterium signal was observed in the aromatic region of the ${ }^{2} \mathrm{H}$ NMR spectrum of the products that were soluble in pyridine. Second, if the alkylation reaction proceeds with coal as th doell with pure dibenzofuran, Scheme 1, further anionization is inevitable and ethyl and isopropyl derivatives should be produced. For one thing, the degree of alkylation would be much higher than what was obtained. Hence it is speculated that although dibenzofuran undergoes metallation with super base, such reactions do not take place in onal. This is quite reaconable because conl has other more ucidic protons 
which are readily abstracted by the strong base, in preference to the aromatic hydrogens.

The nature of the carbon acids in Illinois No. 6 coal was studiod by methylation with sethyl-13 $\mathrm{C}$ indide. The ${ }^{13} \mathrm{C}$ NMR spectrum of the pyridine extract of the product, which contains about $46 \%$ of the organic matter, is shown in Figure 1.

Unfortunately, the resonances of the methyl- ${ }^{13} \mathrm{C}$ group span a broad ange and the spectroscopic results do not provide precise information on the sites of Cmethylation. Nevertheless, certain aspects of the spectrum deserve mertion. The very sharp signals sitir 47,29, 20, and 12 ppm arise from the presence of residual tetrabutylammonium hydroxide. Most of the ${ }^{13} \mathrm{C}$ signal intensity apperss from 11 to $28 \mathrm{ppm}$. Elements of this broad signal are consistent with Chamber's view 8,10 that benzylic and fluorenylic positions are selectively methylated. Particularly strong signals occur near 18 and $25 \mathrm{ppm}$. Although it is unwise to make structurid assignments on the basis of chemical shift data alone, these resonances are compatible with the products of methylation of fluorenyl derivatives, the resonance of the methyl group in 9-methylfuorene is at $18 \mathrm{pprn}$, and with the products of methylation of $\alpha$-altylbenzyl derivatives, the resonance of the methyl group in the simplest $\alpha$-alkylbenzyl derivative, isopropylbenzene, is at 24 ppin. The broud band of resonance between 15 and $30 \mathrm{ppm}$ are consistent with the methylation of a variety of compounds ranging from, for exaraple, diarylmethanes, the resonance of the methyl group in 1,1 -diphenylethane is at $22 \mathrm{ppm}$, to dihydrophenanthrenes, the resonance of the methyl group in 9-methyl-9,10dihydrophenanthrene is at 20 ppin. The absence of prominant signals near 27 and 31 ppm, which could arise from 9,9-dimethylfluorene and 2,2-diphenylpropane, respectively, implies that dialkylation is not a significant reaction. Inspite of the 
presence of excess base in the reaction medium, dimethylation does not appear to occur.

Previous studies have also shown that benzylic alkylations are prominant in reduetive alkylation reactions. 21 One very significant difference that distinguishes super base promoted C-alkylation from reductive C-alkylation deserves mention. During reductive alkylation, anoriatic compounds are converted to dihydro derivatives which undergo methylation to yield substances that contain methyl groups bonded to quatemary carbon atoms of curbocysles as illustrated in equation (3).

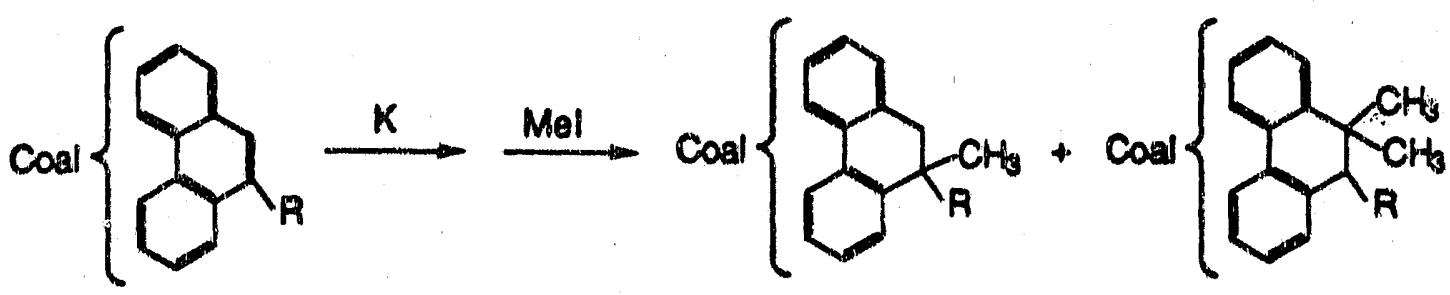

Compounds of this kind exhibit resonances near $30 \mathrm{ppm}$. Such frequencies are absent from the spectrum of the C-alkylation products in Figure 1.

The resonances near 55 and $60 \mathrm{ppm}$ reveal that 0 -methylation of the O-methylated Illinois No. 6 coal also takes place. About 4 methyl groups per $100 \mathrm{~mol} \mathrm{C}$ are introduced during the C-alkylation, and the ratio of C- to O-methylation is approximately 7. These results suggest that about 0.5 new O-methyl groups per $100 \mathrm{~mol} \mathrm{C}$ are introduced into the O-methyl Dlinois No. 6 cosl. Previous studies on anisole showed that it was stable to super base and that orthometallation mether than carbon-oxypen cleavage takes place. 14 Hence, $O$-methyl bond cleavage followed by remethylation with the labelled compound can be ruled out. The treatment of dibenzofuran with super base under the conditions of coal alkylation 
reactions led to the formation of $5 \%$ 2-phenylphenol. Thus, we infer that the new labelled 0-methyl groups arise through base promoted carbon-oxygen bond cleavage reactions in diaryl ethers and heterocycles.

It is pertinent that reductive alkylation reactions cleave about two carbon-oxygen bonds per $100 \mathrm{~mol} \mathrm{C}$ in Illinois No. 6 coal,21 and that the products of reductive alkylation are considerably more soluble than those obtained from super base alkylation. These results imply that the solubilization of Illinois No. 6 coal is significantly enhanced by carbon-oxygen bond cleavage and that such covalent bond cleavage reactions are more important for solubilization than the disruption of polarization forces or hydrogen bonding interactions by the introduction of $\mathrm{O}$ - and C-alkyl groups.

The results for the subbiturninous Wyodak coal are shown in Tables III and IV.

Surprisingly, sodium amide provides a more soluble product than super base for both pristine and O-methylated Wyodak coal. The pristine coal is only $9 \%$ soluble in pyridine. Super base promoted octylation of Wyodak coal produces $33 \%$ soluble material, but mere 0-octylation with tetrabutylammonium hydroxide produces even more soluble material, 37\%. With sodium amide, the product is about $40 \%$ soluble in pyridine. None of the other reaction conditions yielded better results for this coal.

The reactions of O-methylared Wyodak coal with super base and different electrophiles are eummarized in Table IV. It was surprising to find that the products that were obtained in these reactions were less soluble than the products with sodium amide. The reason for the "failure" of super base to improve the 
solubilization of Wyodak coal is not understood. We hope to obtain more information about this observation in our future work.

One of the most notable features of the work with super base and the other $\mathrm{C}$ alkylation reactions centers in the observation that greater success is realized with higher rank coals. Lazarov and his associates pointed out this fact in their work with European coals, ${ }^{6}$ and our work with Lower Kittanning coal is paralled by the observation at the Argonne National Laboratory that Pocahontas No. 3 coal, APCSP 5. which contains $91 \% \mathrm{C}$, is converted by super base to products that are at least $55 \%$ soluble in pyridine. 22

A few points about the nature of the super base promoted C-alkylation need to be mentioned before we discuss the reasons for thi ; difference. The coal reaction system is quite complex and an adequate interpretation of the results requires an appreciation of several aspects of chemistry. First, irreversible reactions occur between the carbon acids in the solid coal and the bases to provide butane and the coal anions which remain in the solid phase. Second, conturrent proton transfer reactions take place between the anions that are formed first and the other carbon acids in the coal and promote the formation of an equilibrated mixture of the most thermodynamically stable coal anions. Third, the addition of the alkylating agent initiates a new set of reactions betwen the anions and the electrophile. These reactions are rapid, but proton transfer reactions of the carton acids in coal may continue during this step. Under these circumstances, both kinetic and thermodynamic factors could influence the outcome of the solubilization experiment. Proton transfer occur reversibly, but alkylation is an irreversible reaction. The situation is illustrated in Scheme 2 for two different carbon acids in coal. 
The physical organic analysis of this problem is embodied in the Curtin-Hammett principle. ${ }^{23}$ if the rates of the alkylation reactions with rate constants $k_{2}$ and $k_{3}$ are slow relative to the rate of proton transfer with rate constants $k_{1}$ and $k_{-1}$, then the ratio of the individual alkylated products, $\mathrm{CoalR} \mathrm{CH}_{3} / \mathrm{CoalR} \mathbf{C H}_{3}$, would reflect the activation energies for the alkylation reactions. However, if the rates of the alkylation reactions are fast relative to the rates of proton transfer, then the product ratio would depend on the relative thermodynamic stability of the carbanions. The more stable the anion, the greater the yield of its alkylation product. The simple situation for a homogeneous solution is greatly complicated jy the heterogeneity of coal. Nevertheless, our results and Chamber's results appear to be best accommodated by an explanation that is based upon the reaction pathway in Scherne 2 and that presumes carbanion equilibration. For example, we were unable to detect products of alkylation at aromatic carbon atoms even though the bases that were used in the reaction were capable of abstracting protons from such positions. Thus, it is reasonable to presume that aryllithiums may be formed in initial reactions, but are converted to more stable substances in subsequent equilibrium conerolled processes.

The differences in solubility of the alkylated high and low rank coais presumably depend upon an array of factors including major differences in molecular structures of the original coals and the array of inter- and intramolecular forces that operate in the liquid and solid state. We believe that the differences in the effectiveness of $\mathrm{C}$ alkylation for the solubilization of low and high rank coals originate in the differences in molecular structure. It is very well known that many properties of coal are a discontinuous function of rank, 24 and we advanced the view that had previously been suggested by Wender 25 that the success of C-alkylation depended upon the degree of coalification, with higher rank coals more susceptible to 
solubilization as a consequence of their lessened structural complexity.9 In point of fact, Ouchi and his coworkers pointed out that the average molecular weights observed for the high rank coals seem to be smaller than the corresponding values for the low rank coals, and proposed that the high ranking coals had more highly condensed aromatic rings but a lower degree of polymerization. ${ }^{26}$ More recently, Larsen and Wei have also concluded from their work that the amount of pyridine extract and average molecular weight increases with the rank upto a carbon content of $86 \% .27$ On the basis of the increase in the quantity of the extractable material with rank and change in molecular weight of the extracts, they also conclude that the coalification process is a net depolymerization. ${ }^{27}$

Our results are compatible with this concept. The lower degree of solubilization of the low rank coals is compatible with the notion that the macromolecular network is larger and more complex. In this situation, a low degree of C-alkylation is inadequate for the achievernent of solubilization because covalent bonding and molecular dimensions dictate the outcome rather than intermolocular interactions such as hydrogen bonding or polarization forces. Thus, for the low rank coals, conventional bond cleavage is required for depolymerization and solubilization. In contrast, the lower degree of polymerization of high rank coals reduces the challenge considerably. In some situations, it may only be necessary to disrupt the intermolecular polarization forces between the aromatic and hydroaromatic molecules to achieve solubilization. As has been mentioned earlier, destruction of such interactions lead to almost quantitative solubilization for the high rank coals. 


\section{fcknowledgement}

This research was supported in part by the United States Deparment of Energy and the Link Foundation which awarded a predoctoral fellowship to Kuntal Chatterjee. 


\section{References}

1.Davison, R.M. Coal Science, 1982, 1, 84,

2. Stock, L.M. Coal Science, 1982, 1, 161.

3. Mallya N. and Stock L.M., Fuel, 1986, 65, 736.

4. Ignasiak B.; Carson D. and Gawalak M., Fuel, 1979, 58, 833.

5. Gawalak, M. ; Carson, B. ; Ignasiak, T. ; Strausz, O.P. Preprints of Papers, International Conference on Coal Science, Maastricht, The Netherlands, 1987; pp 57.

6. Lazarov, L.; Marinov, S.P.; Stefanova, M. ; Angelova, G. Preprints of Papers, International Conference on Coal Science, Maastricht, The Netherlands, 1987; pp 745.

7. Lazarov, L.; Marinov, S.P, Fuel, 1987, 66, 185.

8. Chambers, R.R.Jr.; Hagaman, E.W.; Woody, M.C. Polynuclear Aromatic Hydrocarbons ; Ebert, L., Ed., Advances in Chemistry, 217, 1987 ; Chapter-15, pp 255.

9. Miyake M. and Stock L.M., Energy and Fuels, 1988, 2, 815.

10. Chambers, R.R.JJ; Hagaman, E.W.; Woody, M.C. Preprints of Papers, International Conference on Coal Science, Maastricht, The Netherlands, 1987; pp 741.

11. Schlosser M. and Strunk S., Tetrahedron Letters, 1984, 25, 741.

12. Lochmann L.; Pospisil J. and Lim D., Tetrahedron Letters, 1966, 257 ; Lochmann L. and Lim D., J. Organomet. Chem. , 1971, 28, 153.

13. Bates R.B., personal communication.

14. Bates $\mathbb{R} . B . ;$ Siahaan TJ; Suvannachut K.; Vasey S.K. and Yager K.M., J.Org. Chem., 1987, 52, 4605.

15. Liotta R.; Rose K. and Hippo E., J. Org. Chem., 1981, 46, 277. 
16. Meaercker, A., Angew. Chem. Int. Ed. Engl., 1987, 26, 972.

17. Grovenstein, E., Jr., Adv. Organomet. Chem., 1977, 16, 167.

18. Siskin, M. and Aczel, T., Fuel, 1983, 62, 1321.

19. Wachowska, H. Fuel, 1979, 58, 99.

20. Gilman, H.; Young, R. V., J. Am. Chem. Soc., 1934, 56, 1415 ; ibid, 1935, 57, 1121.

21. Alemany, L.B. and Stock, L.M., Fuel, 1982, 61, 1088.

22. Miyake, M., unpulished results.

23. Eliel, E.L.; Allinger, N.L.; Angyal, S. J.; Morrison, G. A., Conformational Analysis, Reprint. 1981, p-28. 'Siginally published : Interscience Publishers, New York, 1965.

24. Chemistry of Coal Utilization, H. H. Lowry Ed., Supplementary Volume, John Wiley and Sons, New York; 1963.

25. Wender, I.; Heredy, L. A.; Neuworth, M. B. and Dryden, I. G. C. Chemical Reactions and the Constitution of Coal In Chemistry of Coal Utilization, Second Supplementary Volume (Ed. M. A. Elliot), John Wiley and Sons, New York; 1981, Chapter 8, 424.

26. Ouchi, K.; Hirano, Y.; Makabe, M. and Itoh, H., Fuel, 1980, 59, 751.

27. Larsen, J. W. and Wei, Y.-C., Energy and Fuels, 1988, 2, 344. 
Table L. Analytical Data for the Coals.

\begin{tabular}{llll}
\hline & Lower & Mlinois & Wyodak \\
& Kittanning & No.6 & \\
& PSOC 1197* & APCSP 3h & APCSP 2b \\
& & & \\
\hline ultimate analysis, w\% & & & \\
C & 89.6 & 77.8 & 72.0 \\
H & 4.8 & 5.7 & 5.7 \\
N & 1.8 & 1.4 & 1.0 \\
S & 1.2 & 2.6 & 0.5 \\
O (by difference) & 2.6 & 12.5 & 20.5 \\
ash & 10.3 & 16.2 & 9.2
\end{tabular}

maceral analysis, wt\%

vitrinite

94.4

88.0

89.0

inertinite

5.6

9.0

10.0

liptinite

0.0

$3.0 \quad 1.0$

The data were provided by the Pennsylvania State University Sample Program. bThe data were provided by the Argonne National Laboratory Primium Sample Program. 
Tabie II. Results for the C-Alkylation of PSOC 1197 Coal.

reaction conditions :

base, solvent, temperature,

time. electrophile

$\begin{array}{ll}\text { alkyl groups } & \text { solubility, } \\ \text { per 100 } & \text { wt \% in } \\ \text { mol C } & \text { pyridineb }\end{array}$

n- $\mathrm{C}_{4} \mathrm{H} \mathrm{H}_{9} \mathrm{Li}+\mathrm{t}-\mathrm{C}_{4} \mathrm{H}_{9} \mathrm{OK}(1: 1)_{0}$ n-heptane, $98{ }^{\circ} \mathrm{C}, \quad \mathrm{NH}_{4} \mathrm{Cl}$

6 hours.

n- $\mathrm{C}_{4} \mathrm{H}_{9} \mathrm{Li}+\mathrm{t}-\mathrm{C}_{4} \mathrm{H}_{9} \mathrm{OK}(1: 1)$, n-heptane, $98{ }^{\circ} \mathrm{C}, \quad \mathrm{n}-\mathrm{C}_{4} \mathrm{Hg}_{9} \mathrm{I}$

4.0

90

6 hours.

$\mathrm{n}-\mathrm{C}_{4} \mathrm{H}_{9} \mathrm{Li}+\mathrm{t}-\mathrm{C}_{4} \mathrm{H}_{9} \mathrm{OK}(1: 1)$, n-heptane, $98{ }^{\circ} \mathrm{C}$,

$\mathrm{n}-\mathrm{C}_{8} \mathrm{H}_{17} \mathrm{I}$

3.0

92

6 hours.

$\mathrm{NaNH}_{2}$, ammonia, $-75^{\circ} \mathrm{C}, 6$ hours

$\mathrm{n}-\mathrm{C}_{4} \mathrm{H}_{9} \mathrm{I}$

2.5

506

n- $\mathrm{C}_{4} \mathrm{H}_{9} \mathrm{Li}$, THF, $25^{\circ} \mathrm{C}, 6$ hours

$\mathrm{n}-\mathrm{C}_{4} \mathrm{H} \mathrm{H}_{9} \mathrm{I}$

1.0

$10 \mathrm{c}$

a The number of alkyl groups that were introduced was estimated from the gain in weight, the results are given to the nearest 0.5 . Approximately 5 wt\% of the original coal could be extracted in pyridine. ${ }^{c}$ Reference 9. 
Table III. Influence of the Base on C-Octylation of Ilinois No.6 Coal (APCSP 3) and Wyodak coal (APCSP 2).

\begin{tabular}{llll}
\hline coal & reaction conditions : & octyl groups & solubility, \\
& base, solvent, temperature, & per & wt $\%$ in \\
time. & $100 \mathrm{~mol} \mathrm{C}$ & pyridine
\end{tabular}

In':nois No. 6

pristine KOH, THF, $25^{\circ} \mathrm{C}, 6$ hours

(OMe) $\quad \mathrm{n}-\mathrm{C}_{4} \mathrm{H}_{9} \mathrm{Li}+\mathrm{t}-\mathrm{C}_{4} \mathrm{H}_{9} \mathrm{OK}(1: 1)$, n-heptane, $98^{\circ} \mathrm{C}, 6$ hours.

(OMe) $\quad \mathrm{NaNH}_{2}$, arismonia, $-75^{\circ} \mathrm{C}, 6$ hours

Wyodak

pristine

pristine

$\mathrm{Bu}_{4} \mathrm{NOH}, \mathrm{THF}, 25^{\circ} \mathrm{C}, 6$ hours

n- $\mathrm{C}_{4} \mathrm{H} 9 \mathrm{Li}+\mathrm{t}-\mathrm{C}_{4} \mathrm{H}_{9} \mathrm{OK}(1: 1)$, n-heptane,

$98{ }^{\circ} \mathrm{C}, 6$ hours.

pristine $\quad \mathrm{NaNH}_{2}$, ammonia, $-75^{\circ} \mathrm{C}, 6$ hours

(OMe) $\quad \mathrm{n}-\mathrm{C}_{4} \mathrm{H}_{9} \mathrm{Li}+\mathrm{t}-\mathrm{C}_{4} \mathrm{H}_{9} \mathrm{OK}(1: 1)$, n-heptane,

$98^{\circ} \mathrm{C}, 6$ hours.

(OMe) $\quad \mathrm{NaNH}_{2}$, ammonia, $-75^{\circ} \mathrm{C}, 6_{\text {hours }}$

\section{5}

33

2.5

43

2.0

32

$2.5 \quad 40$

$2.5 \quad 20$

2.0

32

- The number of octyl groups that were introduced was estimated from the gain in weight, the results are given to the nearest 0.5 . b Approximately $27 \mathrm{wt} \%$ of the Illinois No. 6 coal and $9 \mathrm{wt} \%$ of the Wyodak coal could be extracted into pyridine. 
Table IV. Influence of the Alkyl Group on Pyridine Solubility of Illinois No. 6 (APCSP 3) and Wyodak (APCSP 2) Coal. a

\begin{tabular}{|c|c|c|c|}
\hline coal & electrophile & $\begin{array}{l}\text { alkyl groups per } \\
100 \mathrm{~mol} \mathrm{C}\end{array}$ & $\begin{array}{l}\text { solubility, wt } \% \text { in } \\
\text { pyridine }\end{array}$ \\
\hline
\end{tabular}

Illinois No. 6

(OMe)

(OMe) $\quad \mathrm{NH}_{4} \mathrm{Cl}$

(OMe) $\quad \mathrm{CH}_{3} \mathrm{I}$

(OMe) $\quad \mathrm{n}-\mathrm{C}_{4} \mathrm{H}_{9} \mathrm{I}$

(OMe) $\quad \mathrm{n}-\mathrm{C}_{8} \mathrm{H}_{17} \mathrm{I}$

$\begin{array}{cc}- & 34 \\ - & 40 \\ 4.0 & 46 \\ 4.5 & 39 \\ 2.5 & 43\end{array}$

Wyodak

(OMe)

-

(OMe)

$\mathrm{NH}_{4} \mathrm{Cl}$

$\begin{array}{cc}- & 35 \\ - & 23 \\ 2.0 & 16 \\ 2.5 & 20 \\ 2.5 & 44 c\end{array}$

(OMe)

n- $\mathrm{C}_{4} \mathrm{H}_{9} \mathrm{I}$

(OMe)

n- $\mathrm{C}_{8} \mathrm{H}_{17} \mathrm{I}$

(OMe)

n- $\mathrm{C}_{8} \mathrm{H}_{17} \mathrm{I}$

2.5

34

40

46

39

43

$44^{c}$

all the reactions were carried out with 45 mmoles of super base per gram of coal in refluxing heptane as described in the Experimental Section. ${ }^{b}$ The number of alkyl groups that were introduced was estimated from the gain in weight, the results are given to the nearest 0.5 . $\mathrm{C}$ About 100 mmoles of the base was used in this experiment. 


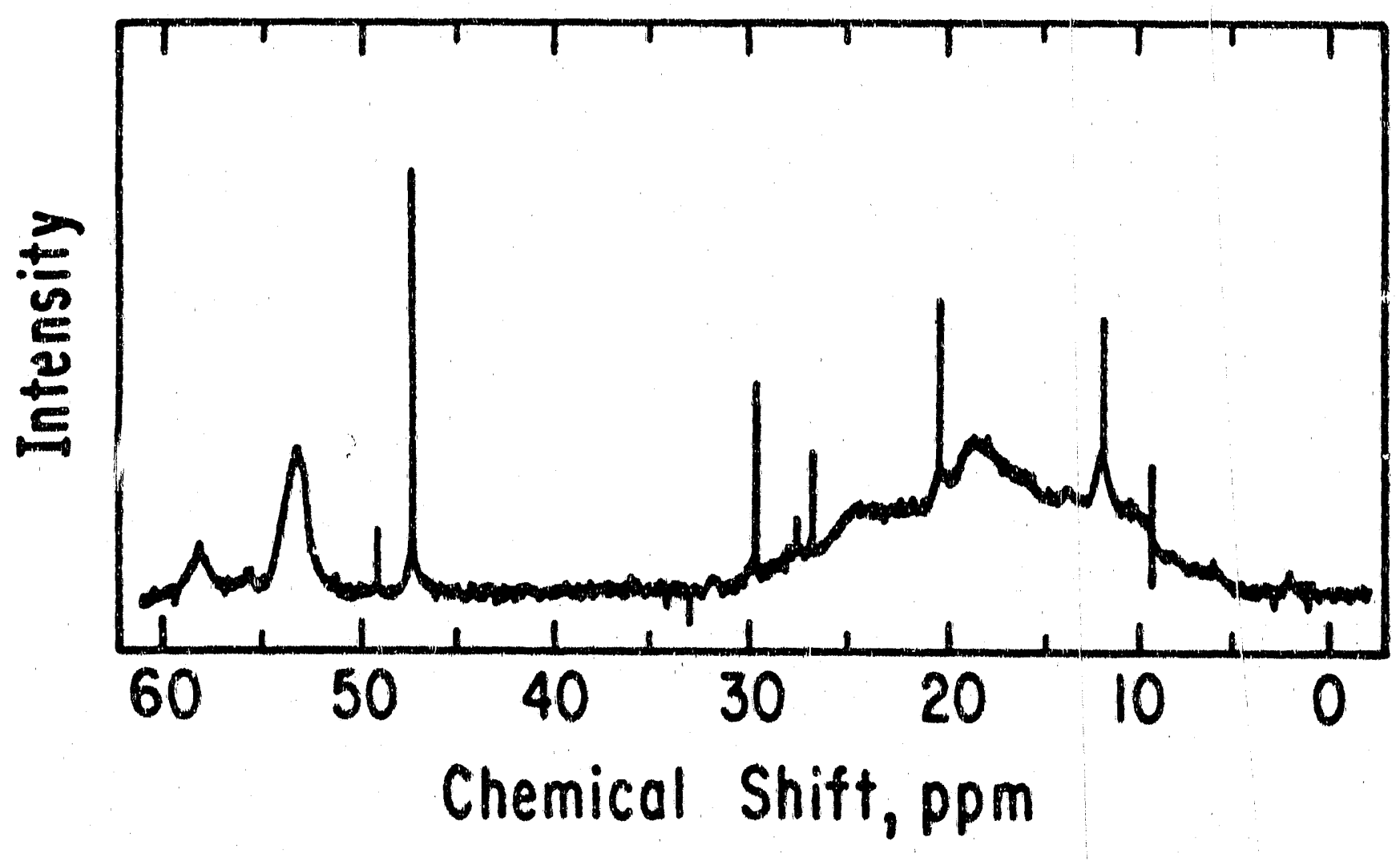

Figure 1. 13C-NMR spectra of the product (pyridine soluble part) of the retaction of alinois No. 6 (OMe) coal with super base and methy!-1.3 C-lodide. The region of interest is between 10 to 60 ppon. 
Scheme 1. Proposed mechanism for the Introduction of more than one methyl group in dibenzofuran.
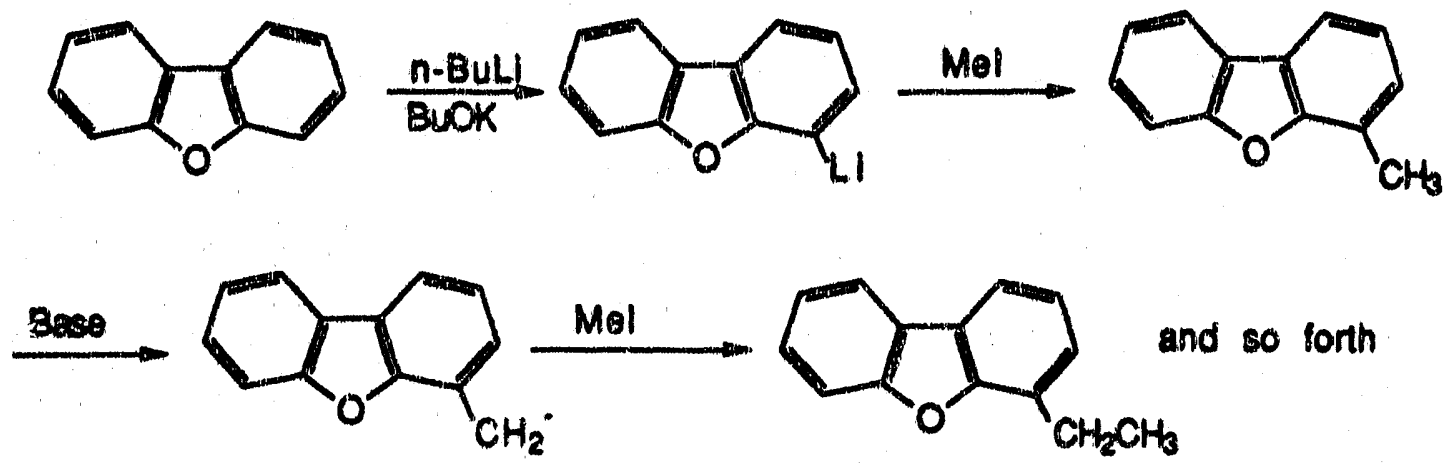
Scheme 2. Curtin-Hammett analysts of coal alkylation.

$$
\begin{aligned}
& (C O A L) R_{1} M^{+}+(C O A L) R_{2} H=\frac{k_{1}}{k_{1}}(C O A L) R_{2} \cdot M^{+}+(C O A L) R_{1} H \\
& k_{2} \mid \mathrm{CH}_{3} \\
& \mathrm{k}_{3} \mathrm{CH}_{3} \\
& (\mathrm{COAL}) \mathrm{R}_{1} \cdot \mathrm{CH}_{3} \\
& (\mathrm{COAL}) \mathrm{R}_{2}-\mathrm{CH}_{3}
\end{aligned}
$$



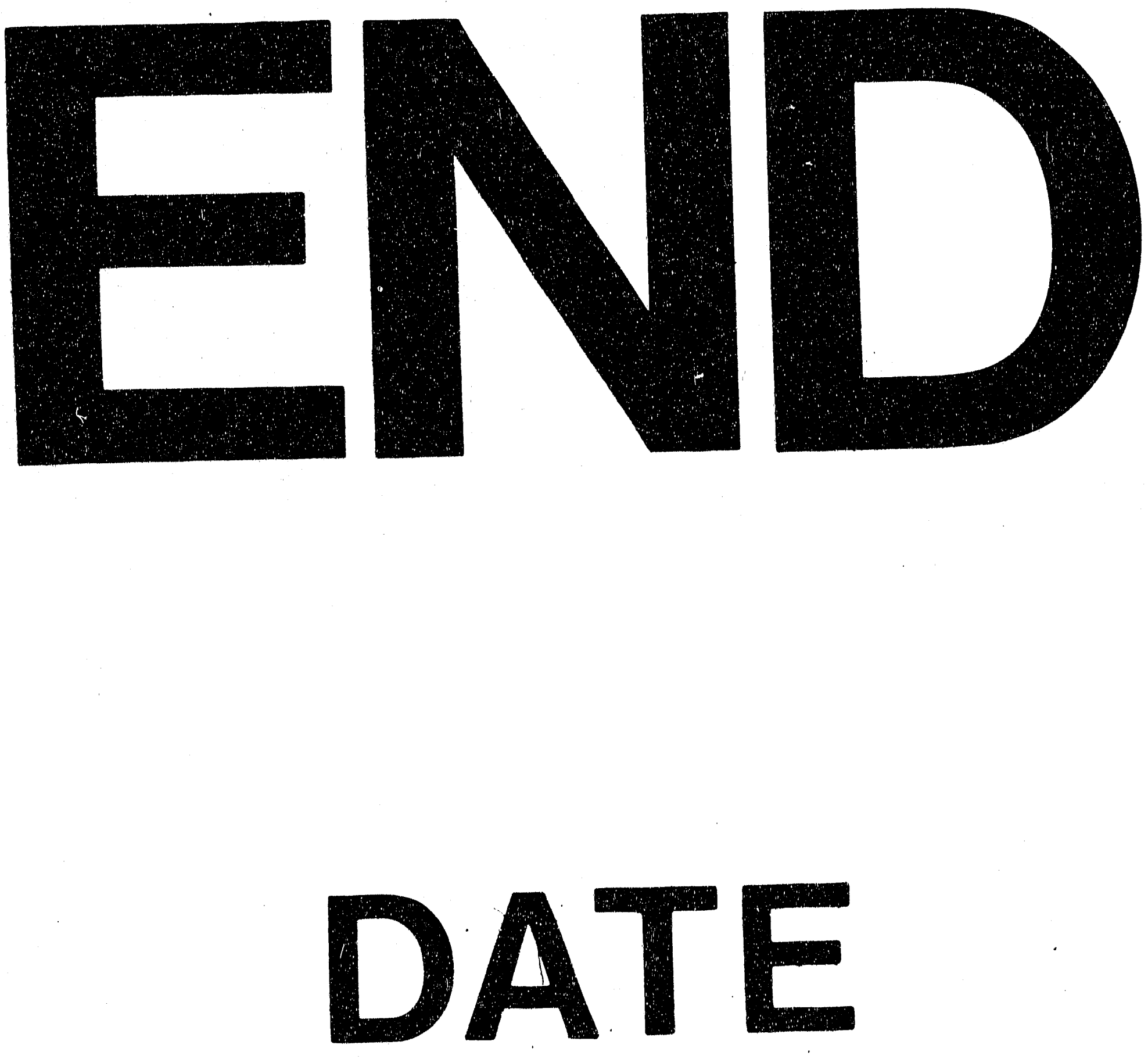

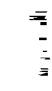

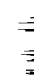
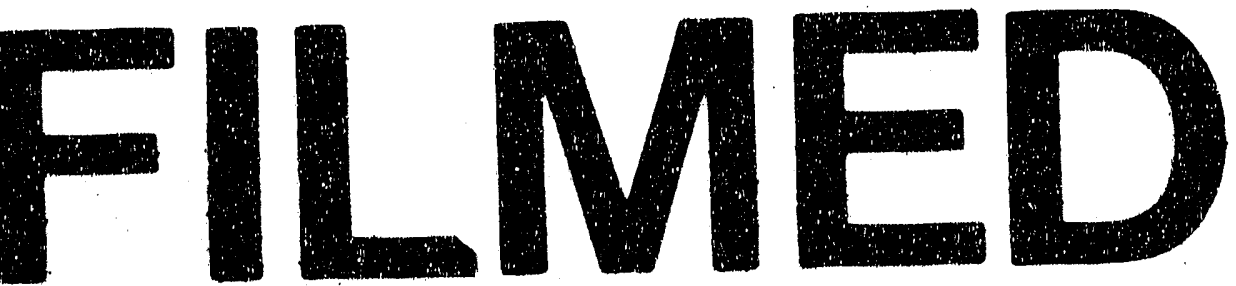

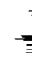

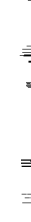

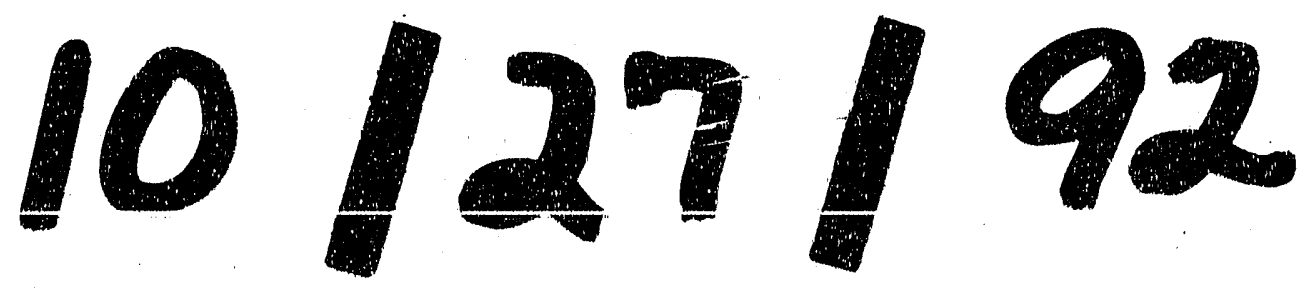

刋 
